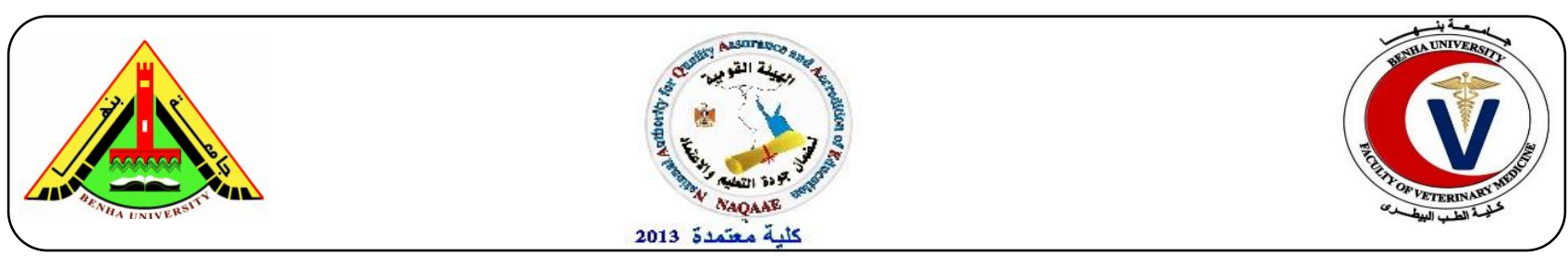

\title{
Assessment of physical and immunological characters of an inactivated avian influenza (H5N1) vaccine prepared using Montanide oil 71 ${ }^{\text {TM }}$ ISA-RVG as adjuvant
}

\author{
El-Sayed, M. H.N1; El-Bagoury, G. F²; El-Habbaa, A. S²; El-Makaky, H. M1 \\ ${ }^{1}$ Newcastle Disease Vaccine Research Department, Veterinary Serum and Vaccine Research Institute, \\ Abbasia, Cairo. \\ ${ }^{2}$ Department of Virology, Faculty of Veterinary Medicine, Benha University.
}

\section{A B S T R A C T}

An inactivated oil-emulsion $\mathrm{H} 5 \mathrm{~N} 1$ avian influenza (AI) vaccine was experimentally formulated with 3 parts of an inactivated avian influenza virus [A/chicken/Egypt/Q1995D/2010 strain-1 and A/duck/Egypt/M2583A/2010 strain-2] emulsified in 7 parts of oil adjuvant. The prepared vaccine was sterile and safe. This water in oil (W/O) emulsion showed zero $\mathrm{mS} / \mathrm{cm}$ conductivity and 22.67 m.pa.s viscosity; this low viscosity reflected on easy injection of the vaccine emulsion. In addition, long duration of stability for 24 months at $+4 \mathrm{C}^{\circ}$. Cell mediated immune response of chicks vaccinated at 21 days age were assessed using lymphocyte blastogenesis and phagocytic activity showed high values from the $3^{\text {rd }}$ day post vaccination (DPV) and continued till $21^{\text {st }}$ DPV. Serum antibody titer against avian influenza virus (AIV) H5N1 was increased from the $1^{\text {st }}$ week post vaccination (WPV) and persisted in high values till $31^{\text {st }}$ WPV using hemagglutination inhibition (HI) test. Efficacy of the prepared vaccine showed $100 \%$ protection in challenged vaccinated chicks. In conclusion, the prepared AI subtype H5N1 vaccine on Montanide ISA-71 showed good humoral and cellular immune responses that could cover two varieties of H5N1 subtypes circulating in Egypt.

Keywords: AI H5N1, inactivated oil-emulsion vaccine, HI test.

(http://www.bvmj.bu.edu.eg)

(BVMJ-34(2): 110-120, 2018)

\section{INTRODUCTION}

Avian influenza (AI) is a viral disease caused by type $\mathrm{A}$ influenza viruses belonging to family Orthomyxoviridae. It causes mild to severe infection in a wide range of domestic birds with the wild bird species are considered to represent the virus natural reservoirs (Olsen et al., 2006).

The virus particle has an envelope with glycoprotein projection with haemagglutinin (HA) and neuraminidase (NA) activity. These two surface antigens are the basis of the serologic identity of the influenza virus using the letters $\mathrm{H}$ and $\mathrm{N}$ with the appropriated numbers in the virus designation. There are 16 HA and 9 NA antigens described among the type A influenza virus (Fouchier et al., 2005; Dugan et al, 2008). AIV have been isolated from more than 90 species of free living birds representing 13 different orders (Alexander, 1982; Alexander and Gough, 
1986; Stallknecht and Shane, 1988; Manvell et al., 2000). AIV can be classified into two categories; low Pathogenic Avian Influenza (LPAI) and High Pathogenic (HPAI) form, based on the severity of illness caused in domestic birds (Capua and Alexander, 2004).

Avian influenza viruses (AIVs) of various subtypes are circulating in poultry (Jeong et al., 2010; Kim et al., 2010). Outbreak of HPAIV H5N1 began in 2003 and continued to spread to almost all Asian countries as well as some countries in Europe and Africa (OIE 2008). In Egypt, HPAIV H5N1 was first reported in poultry in 2006 and was pronounced to be enzootic in 2008 (Aly et al., 2008 and Peyre et al., 2009). It caused sever disease and high mortality in chickens in production farms and village-based production and a great hazard to humans (Aly et al., 2006).

Vaccination is one of the most important control measures against H5N1 highly pathogenic AIV. The world practice showed high effectiveness of counter-epidemic measures in complex with vaccine prophylaxis as it was demonstrated in the USA, Mexico, Pakistan, China, Vietnam, Indonesia, Sudan and Egypt (Peyre et al., 2007).

Quality of the adjuvant emulsion has direct impact on the safety and efficacy of the vaccine, so good physical properties of the inactivated oil vaccine could in turn increase the immune response to this vaccine. High quality oil emulsion vaccine should be stable, with low viscosity to ease injectability and produce suitable Hemagglutinating inhibiting antibody titer in vaccinated birds (stone et al, 1983).

Water -in oil emulsion (W/O) requires high shear homogenization to get stable formulation (Salager 2000: Lissant 1984). So, physiochemical characterization of an emulsion using droplet test, conductivity, viscosity, particle size and stability at various temperatures were required.

The present study was designed to formulate an inactivated H5N1 AIV vaccine using Montanide $^{\mathrm{TM}}$ ISA $71 \mathrm{R}$ VG as adjuvant that would be reflected on the immunological response on vaccinated birds.

\section{Materials and methods}

\subsection{AI Virus strains:}

\section{AI (H5N1) vaccinal strain:}

The Highly pathogenic (HP) Reasortant Avian Influenza Virus $\left(\mathrm{H}_{5} \mathrm{~N}_{1}\right)$ subtype Egypt/ Re-1\&2 strains seed virus obtained from National Research Center (NRC), [A/chicken/ Q1995D/2010 (strain-1) and A/duck/M2583A/2010 (strain-2)]. The virus strains were egg adapted for $8^{\text {th }}$ passage on specific pathogen free-embryonated chicken egg (SPF-ECE) with HA titer $2^{10} / 50 \mu l$ and infectivity titer $10^{9} \quad$ EID50/0.1ml (ElShesheny et al., 2014). It was used for preparation of the inactivated (H5N1) vaccine.

\section{AI H5N1challenge strain:}

Virulent strain of highly pathogenic avian influenza virus (HPAIV) H5N1 subtype (A/Chicken/Egypt/1063/2010) obtained from $\mathrm{NRC}$, with infectivity titer of $10^{5} \mathrm{EID}_{50} / \mathrm{ml}$ used for challenging of vaccinated chicks and kept under observation for 2 weeks.

\subsection{Montanide ISA $71 \mathrm{VG}$ :}

It was obtained from SEPPIC S.A, Paris La Defense. 92806 Puteaux. CEDEX France. Batch No T21931, Product code 36514P. It is a mineral oil-based adjuvant that has been developed for manufacture of water-in-oil (W/O) emulsion.

\subsection{Embryonated Chicken Eggs (ECEs):}

Specific pathogen free embryonated chicken eggs (SPF- ECEs) were purchased from the specific pathogen free egg project, Kom 
Oshim, El-Fayoum Governorate. The eggs were incubated at $37^{\circ} \mathrm{C}$ and $80 \%$ humidity until inoculated at 9-11 days of age via allantoic sac route. They were used for propagation \& titration of the seed influenza viruses used for preparation of the vaccinal patches and testing the safety of prepared inactivated virus suspensions.

\subsection{Experimental chicks:}

Two hundred and ten (210), one-day-old chicks were purchased from specific pathogen free poultry project, Kom Oshim, EL-Fayoum Governorate. They were floor reared, fed on commercial poultry ration, and kept under strict hygienic measures throughout the experiment. The chicks were used for studying the safety and evaluating of the prepared vaccines.

\subsection{Vaccine formulation:}

Propagation of the Virus in SPF-ECEs:

Propagation of AIV [H5N1] strains propagation in SPF-ECEs was applied according to Garcia et al. (1998).

Rapid Plate Hemagglutination (HA) Test:

It was used for detection of AIV $\mathrm{n}$ harvested egg fluid and carried out according to the standard method described by Anon (1971).

Virus Titration in SPF-ECEs:

Estimation $\mathrm{EID}_{50}$ of the viruses used were calculated according to Reed and Meunch (1938).

Inactivation of Viruses:

Formalin working solution (0.37) formalin, $\mathrm{HCHO}, 37 \%$ Analar, $\mathrm{BDH}$, it was diluted in 1:10 formalin to saline ratio in AIVs according to OIE manual, (2004).

Vaccine preparation:

Inactivated Monovalent [H5N1] Montanide TM ISA 71-RVG oil adjuvanted vaccine was prepared as water in oil emulsion by mixing $30 \mathrm{~g}$ of the inactivated AI virus Strain H5N1 mixed in $70 \mathrm{~g}$ of Montanide ${ }^{\mathrm{TM}}$ ISA $71 \mathrm{RVG}$ oil adjuvant according to (Ben Arous et al., 2013).

2.6. Quality control of the prepared vaccines: Sterility test:

Experimental batch of the prepared vaccine was tested for sterility and freedom from any fungal or bacterial contaminants by culturing on specific media (Saburaoud glucose agar searching for fungus contamination after incubation at $25^{\circ} \mathrm{C}$ for 14 days, Nutrient agar media and Thioglycolate broth searching for aerobic and anaerobic bacterial contamination, respectively after incubation at $37^{\circ} \mathrm{C}$ for 72 hours).

Safety test:

A group of 10 chicks of 3 weeks old were inoculated with 2 field doses $(1 \mathrm{ml})$ of the prepared vaccine at the nap of the neck in addition to a control non-vaccinated group. The vaccinated chicks were observed for 2 weeks for any signs of local reaction or appearance of any clinical signs. After 5 days of inoculation, some birds were subjected to post mortem examinations to detect any pathological lesions.

Physical stability:

Physical properties of the emulsions were determined as describe by Brugh et al. (1983) and stone (1987), as Drop test, Real time test and Rheology test (Viscosity test).

\subsection{Experimental design:}

Two hundred, one-day old SPF chicks were housed in brooder units within isolation facilities till they became 21 days of age, then it divided into 2 main groups (100 chicks/ each). Group1 vaccinated with inactivated AI (H5N1) vaccine. Group2 Control (nonvaccinated). Each vaccinated chick received $0.5 \mathrm{ml}$ of the prepared vaccine subcutaneously. Chicks in both groups were used for evaluation of cell mediated and humoral immune response as well as a challenge experiment was carried out to 
determine the potency of the prepared vaccines.

\subsection{Samples:}

Whole blood samples:

Jugular blood samples from vaccinated and non-vaccinated chicks were collected with anticoagulant (Heparin 20-40 IU/ml) at 3, 7, 10, 14, 21 and 28 days post vaccinations for lymphocyte blastogenesis assay and phagocytic activity test.

Serum samples:

Serum samples were collected from all chicks (vaccinated and non- vaccinated) weekly till $10^{\text {th }}$ week post vaccination then every 2 week till the $31^{\text {th }}$ week post vaccination. The sera were inactivated at $56^{\circ} \mathrm{C}$ for 30 minutes, and then stored at $-20^{\circ} \mathrm{C}$ until used in $\mathrm{HI}$ test.

\subsection{Evaluation of cellular immune response} for prepared vaccine:

Evaluation of lymphocyte transformation:

Separation of lymphocytes, determination of viable cell number, and setting up of lymphocytes was performed depending on the instructions of cell proliferation (XTT) kit (ATCC, USA) and the test was performed according to Scudiero et al., (1988). The test was applied according to the method described by Lucy, (1977) and Lee, (1984).

Evaluation of phagocytic activity of chicken macrophages by using Candida Albicans:

Separation of macrophages by ficol hypaque and cultivation of mononuclear cells were performed according to Richardson and Smith, (1981) and modified by Hussien, (1989) .The percent of phagocytosis and phagocytic index was calculated as follow:

phagocytic percentage $=\frac{\text { no of phagocytes which ingest Candida }}{\text { total no of phagocytes }} \times 100$

phagocytic index $=\frac{\text { total no of phagocytes which ingest more than two Candida }}{\text { total no of phagocytes which ingest Candida }}$

Evaluation of the humoral immune response

for prepared vaccines using Hemagglutination (HA) and

Hemagglutination inhibition (HI) test:
The Hemagglutination (HA) and hemagglutination inhibition (HI) test were carried out following the recommendation of (OIE-Manual, 2004). The reagents required for the test are isotonic PBS $(0.1 \mathrm{M}), \mathrm{pH} 7.0$ 7.2 , citrated chicken red blood cells (RBCs) was taken from adult SPF chicken. Cells were washed three times in PBS before use as a $1 \%$ (packed cell v/v) suspension. The used antigens in HI test were prepared from the pure, well identified homologous AIVs (A/chicken/ Q1995D/2010) and (A/duck/M2583A/2010) and the pure, well identified heterologous AIV-challenge strain (A/Chicken/Egypt/1063/2010), (Swayne and Kapczynski, 2008; OIE, 2015). Positive and negative control antigens and antisera should be run with each test, as appropriate.

\subsection{Challenge of chicks vaccinated with AI} vaccine:

Groups of SPF chickens vaccinated at 3 weeks of age were challenged at 28 days post vaccination using virulent $\mathrm{AI}$ virus $\mathrm{H} 5 \mathrm{~N} 1$ as $0.1 \mathrm{ml}$ intranasally. Group 1 of vaccinated chicks (50 birds) were challenged with local Egyptian HPAI H5N1 isolates containing 105 $\mathrm{EID} / \mathrm{ml}$ (OIE 2015). A group of chicks (50 birds) were kept as control unvaccinated and challenged with the same dose of the challenge virus. Birds were observed daily for 10 days post challenge (pc). Three days pc, the morbidity and mortality rates were recorded for each group till the end of the observation period to measure the protection $\%$.

Protection $\%=\frac{\text { No.of survival }}{\text { total No.of challenge of birds }}$ X100

\section{RESULTS}

Propagation and titration of Avian Influenza (H5N1) strains on SPF-ECEs:

Propagated AI virus (H5N1) strains on 10 day old, SPF-ECE had an infectivity titers on 
SPF-ECE and HA titers $10^{9}$ EID $_{50} / \mathrm{ml}$ and $2^{10} \mathrm{HA}$ activity $/ 50 \mu \mathrm{l}$, respectively.

Sterility and safety of the prepared vaccine:

The prepared vaccines were free from aerobic and anaerobic bacteria and fungi. They were completely inactivated as indicated by absence of any pathological lesions, HA activity and/or deaths of inoculated embryos being inoculated in 9 days old, SPF-ECEs through the allantoic sac and candled daily for 6 days. There was no local or systemic reaction and no mortalities among vaccinated chicks indicating safety of the prepared AI vaccines.

Assessment of physical characters of the prepared vaccine:

The prepared vaccine was ensured to be water-in-oil (w/o) emulsion type using drop test, this W/O emulsion showed zero $\mathrm{mS} / \mathrm{cm}$ conductivity, 22.67 m.pa.s viscosity and long duration stability for 24 months at $+4 \mathrm{C}^{\circ}$ with no separation as water release or oil release as shown in table (1).

\section{Cell mediated immune response:}

Significant cell proliferation expressed by optical density was induced in vaccinated chicks from the $3^{\text {rd }}$ day post vaccination (DPV) and increased to reach a maximum value $14^{\text {th }}$ DPV. This result was compared with that of non-vaccinated chicks kept as negative control that had no lymphocyte proliferation as shown in table (2). Both phagocytic percent and phagocytic index of macrophages were significantly increased $7^{\text {th }}$ DPV in vaccinated chicks to reach maximum values at $14^{\text {th }} \mathrm{DPV}$, when compared with that of non-vaccinated chicks kept as negative control that had lower macrophage activity as shown in table (3).

\section{Humoral immune response:}

It was noticed that vaccinated chicks showed increased mean $\log 2 \mathrm{HI}$ antibody titer (4.33 $\log 2$ ) from the 1 st week post vaccination (WPV), then reached the highest HI antibody titer $(9.66 \log 2)$ at the $4^{\text {th }} \mathrm{WPV}$, then declined to $(4.3 \log 2)$ at the $31^{\text {st }} \mathrm{WPV}$. The results were compared with that of non-vaccinated chicks kept as negative control that had no antibody against H5N1 as shown in table (4).

Potency of the prepared vaccine:

Both vaccinated and non-vaccinated control chicks were challenged 28 days post vaccination using virulent strain of HPAIV H5N1 subtype. The protection percent were $100 \%$ in vaccinated chicks compared with $0 \%$ for control non-vaccinated chicks as shown in table (5).

Table 1: Stability values of the inactivated AI (H5N1) vaccine with Montanide oil ISA 71 TM -RVG as adjuvant.

\begin{tabular}{|c|c|c|c|}
\hline $\begin{array}{c}\text { Time of check } \\
\text { post manufacture }\end{array}$ & $+4^{\circ} \mathrm{C}$ & $+25^{\circ} \mathrm{C}$ & $+37^{\circ} \mathrm{C}$ \\
\hline 1 day & Stable & Stable & Stable \\
\hline 1 week & Stable & Stable & Stable \\
\hline 2 weeks & Stable & Stable & Stable \\
\hline 1 month & Stable & Stable & Stable \\
\hline 3 months & Stable & Stable & $\begin{array}{l}\text { Water release } 15 \% \\
\text { and oil phase } 10 \%\end{array}$ \\
\hline 6 months & Stable & Stable & $\begin{array}{l}\text { Water release } 15 \% \\
\text { and oil phase } 10 \%\end{array}$ \\
\hline 12 months & Stable & Water drop & $\begin{array}{l}\text { Water release } 15 \% \\
\text { and oil phase } 10 \%\end{array}$ \\
\hline
\end{tabular}




\begin{tabular}{|c|c|c|c|}
\hline 15 months & Stable & Water release $15 \%$ & $\begin{array}{l}\text { Water release } 15 \% \\
\text { and oil phase } 10 \%\end{array}$ \\
\hline 18 months & Stable & Water release $20 \%$ & $\begin{array}{l}\text { Water release } 25 \% \\
\text { and oil phase } 15 \%\end{array}$ \\
\hline 21 months & Stable & Water release $35 \%$ & $\begin{array}{l}\text { Water release } 25 \% \\
\text { and oil phase } 15 \%\end{array}$ \\
\hline 24 months & Stable & Water release $35 \%$ & $\begin{array}{l}\text { Water release } 25 \% \\
\text { and oil phase } 15 \%\end{array}$ \\
\hline
\end{tabular}

Table 2: lymphocyte blastogenesis of chicks vaccinated with inactivated AIV (H5N1) vaccine with Montanide oil ISA $71^{\mathrm{TM}}-\mathrm{RVG}$ as adjuvant.

\begin{tabular}{ccc}
\hline $\begin{array}{c}\text { Days post } \\
\text { vaccination }\end{array}$ & $\begin{array}{c}\text { Cell proliferation expressed by optical density } \\
\text { Vaccinated chicks }\end{array}$ & \begin{tabular}{c} 
Control chicks \\
\hline $3^{\text {rd }}$
\end{tabular} \\
$7^{\text {th }}$ & 0.655 & 0.173 \\
$10^{\text {th }}$ & 1.4405 & 0.198 \\
$14^{\text {th }}$ & 1.5205 & 0.397 \\
$21^{\text {th }}$ & 1.945 & 0.2452 \\
$28^{\text {th }}$ & 0.8295 & 0.184 \\
\hline
\end{tabular}

Table 3: Macrophage activity of chicks vaccinated with inactivated AIV (H5N1) vaccine with Montanide oil ISA $71^{\mathrm{TM}}-\mathrm{RVG}$ as adjuvant.

\begin{tabular}{ccccc}
\hline \multirow{2}{*}{$\begin{array}{c}\text { Days post } \\
\text { vaccination }\end{array}$} & \multicolumn{2}{c}{ Phagocytic activities days post vaccination } \\
\cline { 2 - 5 } & $\begin{array}{c}\text { Paccinated } \\
\text { chicks }\end{array}$ & $\begin{array}{c}\text { Control } \\
\text { chicks }\end{array}$ & $\begin{array}{c}\text { Vaccinated } \\
\text { chicks }\end{array}$ & $\begin{array}{c}\text { Control } \\
\text { chicks }\end{array}$ \\
\hline $7^{\text {th }}$ & $66.66 \%$ & $5.26 \%$ & 0.55 & 0.08 \\
$14^{\text {th }}$ & $88.88 \%$ & $3.703 \%$ & 0.90 & 0.11 \\
\hline
\end{tabular}

Table 4: Mean $\log _{2} \mathrm{HI}$ antibody titers in chicks vaccinated with inactivated AIV (H5N1) vaccine with Montanide oil ISA $71^{\mathrm{TM}}-\mathrm{RVG}$ as adjuvant.

\begin{tabular}{cc}
\hline Weeks post vaccination & $\begin{array}{c}\text { Mean } \log _{2} \text { HI serum } \\
\text { antibody titer } \\
\text { for AIV H5N1 /ml }\end{array}$ \\
\hline 1 & 4.33 \\
2 & 8.33 \\
3 & 9.33 \\
4 & 9.66 \\
5 & 9.33 \\
6 & 9.33 \\
7 & 8.66 \\
8 & 8.33 \\
9 & 8.33 \\
10 & 8.33 \\
12 & 8.33 \\
15 & 8.00 \\
17 & 7.33 \\
19 & 7.33 \\
21 & 7.00 \\
23 & 7.00 \\
27 & 5.66 \\
31 & 4.33 \\
\hline
\end{tabular}


$*$ Number of chicks examined $=100$

Table 5: Protection percent in chicks vaccinated with inactivated AIV (H5N1) vaccine with Montanide oil ISA $71^{\mathrm{TM}}-\mathrm{RVG}$ as adjuvant after their challenge with virulent strain of (HPAIV) H5N1.

\begin{tabular}{ccc}
\hline Group & Vaccinated chicks & Control chicks \\
\hline Challenged & 20 & 20 \\
Dead & 0 & 20 \\
Live & 20 & 0 \\
Protection Percent & $100 \%$ & $0 \%$ \\
\hline
\end{tabular}

\section{DISCUSSION}

Vaccination is one of the most important control measures of AI (Peyre et al., 2007). The nature of the adjuvant has coordinate effect on the safety and efficacy of the vaccine. High quality vaccine adjuvant should be stable, with low viscosity to ease injectability and produce suitable immune response in vaccinated birds (stone et al, 1983). This work was planned to prepare and assess physical and immunological characters of an inactivated avian influenza (H5N1) vaccine prepared using Montanide oil $71^{\mathrm{TM}}$ ISA-RVG as adjuvant.

Avian influenza strains (H5N1) were separately propagated in 10 days old, SPFECE, and the allantoic fluid was harvested and tested for sterility. The virus titers calculated on SPF-ECE using infectivity titration and HA test was $9 \log _{10} \mathrm{EID}_{50} / \mathrm{ml}$ and $10 \log _{2} \mathrm{HAU} / 50 \mu 1$, respectively.

AI virus (H5N1) strains were inactivated separately by formalin $0.1 \%$ and were completely inactivated after $18 \mathrm{hrs}$, which as proved by absence of any pathological lesions, HA activity and/or deaths of inoculated embryos. This result comes in agreement with OIE manual, (2004).

The inactivated AI virus (H5N1) strains were used as the seed virus for vaccine preparation (OIE, 2008) in the formula of W/O emulsion using Montanide ${ }^{\text {TM }}$ ISA 71 RVG adjuvant according to the instructions of the manufacturing company, SEPPIC, France. The W/O emulsion vaccine need high shear homogenization to get stable formulation (Lissant, 1984 and Salager, 2000). The prepared vaccine was ensured to be water-inoil (w/o) emulsion type using drop test, this W/O emulsion showed zero $\mathrm{mS} / \mathrm{cm}$ conductivity. These results were agreed with (Lissant 1984 and Salager 2000).

Vaccine viscosity will reflect on the degree of resistance by which the vaccine flows which reflects on the injectability of vaccine. The prepared vaccine had 22.67 m.pa.s viscosity and this result agree with acceptance limits of viscosity of vaccine emulsion ranged between $12 \geq \mathrm{R} \leq 56$ mpa.s. (European pharmacopeia, 2010), indicating suitable flow time and easy injectability.

The prepared vaccine was ensured to have long duration stability for 24 months at $+4 \mathrm{C}^{\circ}$ with no separation as water release or oil release as shown in table (1), (Ben Arous et al., 2013 and El-Sayed, 2014).

The prepared vaccine was ensured to be sterile and safe. No bacterial or fungal contaminants were shown on specific bacteriologic and fungal media. In addition, absence of local and systemic reactions and no mortalities were recorded in inoculated chicks which denoted to the safety of the prepared vaccines (OIE-Manual, 2004).

Assessment of cell mediated immune response showed significant lymphocyte 
proliferation in vaccinated chicks from the $3^{\text {rd }}$ day post vaccination (DPV) and increased to reach a maximum value $14^{\text {th }} \mathrm{DPV}$. This result was compared with that of non-vaccinated chicks kept as negative control that had lower lymphocyte proliferation as shown in table (2). Both phagocytic percent and phagocytic index of macrophages were significantly increased $7^{\text {th }}$ DPV in vaccinated chicks to reach maximum values at $14^{\text {th }} \mathrm{DPV}$, when compared with that of non-vaccinated chicks kept as negative control that had no macrophage activity as shown in tables (3). These results indicated clearly that chicken vaccinated with oil emulsion vaccine greatly stimulated the cellular immune response as estimated by lymphocyte proliferation test (Madkour 1992). Values of cellular immune response decrease at later stages once the humoral immune response become established (Timms and Bracemell, 1983).

High immunogenicity of the inactivated AI virus $\mathrm{H} 5 \mathrm{~N} 1$-vaccine emulsified using Montanide ${ }^{\mathrm{TM}}$ ISA- 70 as oil adjuvant were shown in table (4). HI antibodies were detected in 14 days and reached their peak of in the $6^{\text {th }} \quad$ week post vaccination (Zhailyaubay et al., 2010). Suitable HI antibody titers also appeared 7 to 10 days after vaccination which reached the peak at 3 to 4 weeks and last up to 6 to 12 months (Swayne et al., 1997, Swayne et al., 2000 and Qiau et al., 2006).

The protection percent were $100 \%$ in vaccinated chicks with the prepared vaccine (table 5).

Similar results showing hemagglutinating antibodies were detected in 14 days and reached their peak in the 6th WPV, protection percent were $100 \%$ against infection since 28 day post vaccination up to 150 days; then slowly going down to $80 \%$ (the rate sufficient for ensuring safety of the vaccinated poultry) by the $360^{\text {th }}$ day post vaccination (Zhailyaubay et al., 2010).

In conclusion, it was found that the prepared inactivated AI (H5N1) vaccine with Montanide $^{\mathrm{TM}}$ ISA 71-RVG oil adjuvant. Improved the physical properties of prepared vaccine as stability and inject ability and have a positive effect on cellular immune responses and improved the obtained serum antibody responses as assured by challenge test.

\section{REFERENCES}

Alexander, D.J. 1982. Avian influenza. Recent developments. Vet Bull 52:341-359.

Alexander, D.J.; Gough, R.E. 1986. Isolations of avian influenza virus from birds in Great Britain. Vet Rec 118:537-538.

Aly, M.M.; Arafa, A.; Hassan, M.K. 2008. Epidemiological findings of Outbreaks of disease caused by highly pathogenic H5N1 avian influenza virus in poultry in Egypt during 2006: Avian Diseases 52, 269-277.

Aly, M.M.; Hassan, M.K.; Arafa, A. 2006. Emergence of highly pathogenic H5N1 avian influenza virus in poultry in Egypt. First record of 2006 outbreaks. J. Egypt. Vet. Med. Assoc., vol.66 (2): 263-

Anon, 1971. Methods of examine poultry biologics for identifying and quantifying avian pathogens. Nat. Acad. Sci. Washington DC.

Ben Arous, J.; Deville, S.; Norkina, S.; Borisov, V.; Rozhdestvenskaia, T.; Rozhdestvenskiy, I.; Gaucheron, J.; Dupuis, L. 2013. Montanide ${ }^{\text {TM }}$ ISA 71 RVG: A robust and flexible adjuvant formulation for potent and stable poultry vaccines. Egg-Broiler, September 2013, www.vivekanandapublications.info.

Brugh, M,; Stone, H.D.; Lupton, H.W. 1983. 
Comparison of inactivated Newcastle disease viral vaccines containing different emulsion adjuvants. Am. J. Vet. Res.; 44(1):72-75.

Capua, I.; Alexander, D.J. 2004. Review Article Avian influenza: recent developments Avian Pathology., 33(4), 393-404.

Dugan, V.G.; Chen, R.; Spiro, D.J.; Sengamalay, N., Zaborsky, J.; Ghedin, E.; Nolting, J.; Swayne, D.E.; Runstadler, J.A.; Happ, G.M.; Senne, D.A., Wang, R.; Slemons, R.D.; Holmes, E.C.; Taubenberger, J.K. 2008. The evolutionary genetics and emergence of avian influenza viruses in wild birds. PloS Pathogens, Volume 4, Issue 5, www.plospathogens.org. https://doi.org/10.1371/journal.ppat.10 00076

El-Sayed, M.H.M. 2014. Improving the physical characters and immunological response of locally prepared oil emulsion ND vaccine, Thesis for the degree of P.H.D., (Virology) Faculty of Veterinary Medicine, Benha University.

El-Shesheny, R., Kandeil, A., Bagato, O., Maatouq, A.M., Moatasim, Y., Rubrum, A., Song, M.S., Webby, R.J., Ali, M.A., Kayali, G. 2014. Molecular characterization of avian influenza H5N1 virus in Egypt and the emergence of a novel endemic subclade. J. Gen. Virol. 95 (PT 7), 1444-1463.

European pharmacopeia 7th rev 2010 p27.

Fouchier, R.A.; Munster, V.; Wallensten, A.; Bestebroer, T.M.; Herfst, S.; Smith, D.; Rimmelzwaan, G.F.; Olsen, B.; Osterhausm, A.D. 2005. "Characterization of a novel influenza A virus haemagglutinin subtype (H16) obtained from black-headed gulls", J. Virol. 79 (5): 2814-22.
Garcia, M.; Suarez, D.J.; Crawford, J.M.; Latimer, J.W.; Slemons, R.D.; Swayne, D.E.; Perdue, M.I. 1998. Evaluation of H5 subtype avian influenza A viruses in North America. Virus Res.51, 115124.

Hussein, H.A. 1989. Immunosuppressive effect of MDV. M.V.SC, thesis (Virology), Faculty of Veterinary Medicine, Cairo University.

Jeong, O.M.; Kim, Y.J.; Choi, J.G.; Kang, H.M.; Kim, M.C.; Kwon, J.H.; Lee, Y.J. 2010. Genetic characterization of H1 avian influenza viruses isolated from migratory birds and domestic ducks in Korea. Virus Genes; 42:5563.

Kim, J.K., Kayali, G.; Walker, D.; Forrest, H.L.; Ellebedy, A.H.; Griffin, Y.S.; Rubrum, A.; Bahgat, M.M.; Kutkat, M.A.; Ali, M.A.; Aldridge, J.R.; Negovetich, N.J.; Krauss, S.; Webby, R.J.; Webster, R.G.; 2010. Puzzling inefficiency of $\mathrm{H} 5 \mathrm{~N} 1$ influenza vaccines in Egyptian poultry. Proc. Natl. Acad. Sci. USA 107:1104411049.

Lee, L.F. 1984. Proliferative response of chicken $\mathrm{B}$ and $\mathrm{T}$ lymphocyte to mitogen.Vet.Med; 15:44-52.

Lissant, K.J.L. 1984. Emulsions and emulsion technology, part III. In: Lissant Kenneth J, editor. Surfactant Science Series, vol. 6, pp:206-10.

Lucy, F.L. 1977. Chicken Lymphocyte stimulation by mitogenes. A microassay with whole blood cultures. Avian Dis.; 22,296-307.

Madkour, M.S. 1992. Study of immunological comparative on live and killed Newcastle disease vaccine in poultry. M.D.V.Sci. (Immunology), Cairo university.

Manvell, R.J.; McKinney, P.; Wernery, U.; Frost, K.M. 2000. Isolation of a highly 
pathogenic influenza (A) virus of subtype H7N3 from a peregrine falcon (Falco peregrinus). Avian Pathol 29:635-637.

OIE-Manual, 2004. Manual of standards of diagnostic tests and vaccines. Avian infectious bronchitis, 4th edn. pp. 569 561.

OIE, 2008. Manual of Diagnostic Tests and Vaccines for Terrestrial Animals, Office International des Epizooties, Paris, France: Pp.: 443-455.chapter 2.3.2. World Organization for Animal Health.

OIE, 2015. Emerging Respiratory Pathogens bulletin: Avian Influenza A(H5N1) and others; MERS-CoV Originally distributed 2015-05-19.

Olsen, B.; Munster, V.J.; Wallensten, A.; Waldenstrom, J.; Osterhaus, A.D. 2006. Global patterns of influenza a virus in wild birds. Science. 312:3848.

Peyre, M.; Desvaux, S.; Fusheng, G. 2007. Avian Influenza Vaccine Development, Practical Application in Developing Countries. Proceedings of the 12th International Conference of the Association of Institutions for Tropical Veterinary Medicine، Montpellier, France 20-22 August.

Peyre, M.; Samaha, H.; Makonnen, Y.J.; Saad, A.; Abd-Elnabi A.; Galal S.; et al., 2009. Avian influenza vaccination in Egypt: limitations of the current strategy. J Mol Genet Med. 3:198-204.

Qiau, Ch.; Tian, G.; Jiang, Y.; Li ,Y.; Shi, J.; $\mathrm{Yu}$, K., Chen, H. 2006. Vaccines Developed for H5 Highly Pathogenic Avian Influenza in China. J Ann. NY Acad Sci, 1081, 182- 192.

Reed, L.J.; Mennch, H. 1938. Simple method for estimating 50 percent end point, Amer. J. Hyg; 27: 793-799.

Richardson, M.D.; Smith, H. 1981. Resistance of virulent and attenuated strains of Candida albicans to intracellular killing by human and mouse phagocytes. J. Infect. Dis.; 144:557-565.

Salager, J.L. 2000. Formulation concepts for emulsion maker. In: Nielloud F, Mestres GM. editors pharmaceutical emulsion and suspension and pharmaceutical science; 2000:19-68.

Scudiero, D.A.; Shoemaker, R.H.; Paull, K.D.; Monks, A.; Tierney, S.; Nofziger, T.H.; Currens, M.J.; Seniff, D.; Boyd, M.R. 1988. Evaluation of soluble tetrazolium / Formazan Assay for cell growth and drug sensitivity in culture using human and other tumer cell lines. Cancer Res.; 48:4827-4833

Stallknecht, D.E.; Shane, S.M. 1988. Host range of avian influenza virus in freeliving birds. Vet. Res. Commun. 12, 125-141.

Stone, H.D. 1987. Efficacy of avian influenza oil-emulsion vaccines in chickens of various ages. Avian Dis., 31: 483-490.

Stone, H.D.; Brugh, M.; Bread, C.W. 1983. "influence of formulation on the efficacy of experimental oil-emulsion Newcastle disease vaccines" Avian Diseases., 27:.688-697.

Swayne, D.E.; Kapczynski, D. 2008. Vaccines, vaccination, and immunology for avian influenza viruses in poultry. In: Avian Influenza. Swayne D.E. ed., Wiley-Blackwell, Ames, Iowa, USA, 407-451.

Swayne, D.E.; Beck, J.R.; Micckle, T.R. 1997. Efficacy of recombinant fowl poxvirus vaccine in protecting chickens against a highly pathogenic Mexicanorgin H5N2 avian influenza virus Avian Dis. 41(4):910-922.

Swayne, D.E.; Garcia, M.; Beck, J.R.; Kinney, N.; Suarez, D.L. 2000. Protection against diverse highly pathogenic avian influenza viruses in 
chickens immunized with a recombinant fowl pox vaccine containing an H5 avian influenza haemagglutinin gene insert. Vaccine 18(11- 12):1088-1095.

Timms, L.M.; Bracemell, C.D. 1983. Cell mediated and humoral immune response of chickens to inactivated oil emulsion infectious bronchitis vaccine. Res. Vet. Sci., 34:224-230

Zhailyaubay, K.K.; Kaissar, K.T.; Sholpan, Zh.R.; Seidigapbar, M.M.; Berik M.K. 2010. "Immunogenicity of the inactivated oil emulsion influenza (H5N1) vaccine in chickens". Agric. Biol. J. N. Am., 1(3): 201-207. 